\title{
Histopathological spectrum of dermatological lesions - An experience at tertiary care centre
}

\author{
Mamatha .K ${ }^{1}$, S. Susmitha, ${ }^{2, *}$ Vijayalaxmi .S Patil ${ }^{3}$, Sathyashree K. $\mathbf{V}^{4}$, Disha B.S ${ }^{5}$ \\ ${ }^{1,3}$ Assistant Professor, ${ }^{2,4,5}$ Post Graduate Student, Dept. of Pathology, BLDE (Deemed to be University), Shri B.M. Patil Medical \\ College, Vijaypura, Karnataka, India \\ *Corresponding Author: \\ Email: susmitha.scrt@gmail.com
}

\begin{abstract}
Introduction: Skin is the largest sensory organ of the body and acts as a barrier against various harmful environmental agents. Thus it is involved in wide spectrum of disorders ranging from inflammatory conditions to neoplastic lesions. Skin biopsy followed by histopathological study is needed for accurate diagnosis, identifying etiological agent with special stains wherever feasible, and to help clinicians to decide the appropriate management.

But for instance, only few statistical studies have been carried out in southern India. Thus, the present study was carried out with an aim of describing the histopathological spectrum of all the skin lesions in a tertiary care hospital. Materials and Methods: The present study is a retrospective study carried out in the Department of Pathology, BLDE (Deemed to be) University, Shri B.M. Patil Medical College, Hospital and Research Centre, Vijayapura, Karnataka. All the skin biopsies received in histopathology section from October 2015 to September 2017 were reviewed from the archives of the department.

Results: Out of 286 skin biopsies with histopathological diagnosis, majority of the cases were belonging to group Vgranulomatous lesions (154 cases), followed by group III (46 cases), group IV (27 cases) and group VI (27 cases), group VII (16 cases), group II (12 cases) and group VIII (4 cases).

Conclusion: Dermatological lesions are heterogeneous with wide age distribution, clinical and histopathological spectrum. Histopathological examination of the skin biopsy remains the gold standard for diagnosis which can be supported with the other techniques to confirm the diagnosis.
\end{abstract}

Keywords: Histopathology, Dermatology and Leprosy.

\section{Introduction}

Skin is the largest sensory organ of the body and acts as a barrier against various harmful environmental agents. Thus it is involved in wide spectrum of disorders ranging from inflammatory conditions to neoplastic lesions. ${ }^{1}$ It is classified into pigment and melanocytic disorders, neoplastic lesions of epidermis, neoplastic condition of dermis, disorders of epidermal maturation.

Dermatological lesions are commonly encountered in all countries and it encompasses a wide spectrum. ${ }^{2}$ It varies from country to country and various regions within a country. ${ }^{3}$ This variation is also influenced by sex, age and associated systemic disorders, economy, literacy, racial and social customs. ${ }^{3}$

Skin problems are most commonly encountered among the health problems in India. ${ }^{2}$ Its prevalence ranges from $6.3-11.16 \% .{ }^{1}$ But most of them are not being regarded as significant problem, because of the presumption that many are benign and not life threatening. ${ }^{4}$ However, some of them requires major medical attention and pose great psychological impact on the quality of life. ${ }^{5}$

Many of the skin lesions are diagnosed clinically based on the history and examination of the lesions. However, some of them requires additional simple diagnostic procedures to get added information to make final diagnosis. Some of them are potassium hydroxide preparation for demonstration of fungal elements,
Tzanck smear, examination under wood's lamp and skin biopsy. ${ }^{6}$ There are various methods of procuring skin biopsies and include punch biopsy, shave biopsy, scalpel biopsy and curettage biopsy. ${ }^{6}$ Skin biopsy followed by histopathological study is needed for accurate diagnosis, identifying etiological agent with special stains wherever feasible, and to help clinicians to decide the appropriate management. ${ }^{4,7}$

Clinicopathological correlation offers a substantial clue in arriving at the diagnosis. ${ }^{2}$ Anatomical location, type of lesion, duration, number and other associated conditions provides a valuable information in confirming the diagnosis. ${ }^{4}$

Granulomatous dermatoses are a group of disorders which are caused by varied etiological agents and includes heterogenous lesions but often share a common histological feature of granuloma formation. Leprosy and tuberculosis occupies the major proportion of this category. ${ }^{8}$ Accurate diagnosis is of atmost importance as the treatment differs for different type of granulomatous lesion. ${ }^{9,10}$

But for instance, only few statistical studies have been carried out in southern India elaborating the diseases which requires histopathological examination to confirm the clinical diagnosis. Thus, the present study was carried out with an aim of describing the histopathological spectrum of all the skin lesions in a tertiary care hospital. 


\section{Materials and Methods}

The present study is a retrospective study carried out in the Department of Pathology, BLDE (Deemed to be) University, Shri B.M. Patil Medical College, Hospital and Research Centre, Vijayapura, Karnataka.

All the skin biopsies received in histopathology section from October 2015 to September 2017 were reviewed from the archives of the department. Clinical history and relevant data were recorded. Slides stained with routine hemotoxylin and eosin stain and special stains such as Ziehl-Neelsen (ZN) stain, periodic acidSchiff, Alcian blue, Fite-Faraco, Verhoeff's and Congo red for amyloid were examined under light microscopy. Further they were classified into various histological categories based on the site and pattern of involvement.

Inclusion Criteria: All skin biopsies received in histopathology section were included in the study.

Exclusion Criteria: Inadequate skin biopsies and inconclusive biopsies were excluded from the study.

\section{Results}

The present study is a retrospective study in which we included all the skin biopsies received at the histopathology section in Pathology department of our institute for the period of two years. Totally 286 cases were included in the study. It includes 136 cases of males and 150 cases of females with wide age groups involved. After histopathological diagnosis, these lesions were further categorized into 8 groups based on the site, pattern of involvement and cytological features, such as

Group I: Disease limited to epidermis and stratum corneum

Group II: Disease with localized superficial epidermal or melanocytic proliferation

Group III: Disease of superficial cutaneous reactive unit Group IV: Disease with acantholytic, vesicular and pustular morphology

Group V: Disease with perivascular, diffuse and granulomatous infiltrate of the reticular dermis

Group VI: Tumors and cysts of the dermis and subcutis Group VII: Inflammatory disorders of skin appendages Group VIII: Disorders of the subcutis

Out of 286 skin biopsies with histopathological diagnosis, majority of the cases were belonging to group V- granulomatous lesions (154 cases), followed by group III (46 cases), group IV (27 cases) and group VI (27 cases), group VII (16 cases), group II (12 cases) and group VIII (4cases).

Maximum number of cases belonged to 51-60 years of age group with females predominating the group (52.4\%).

Among the group II lesions porokeratosis was commonest and constituting to $1.39 \%$ of the total cases (Fig. 1) whereas Lichen planus was commonest reported case in group III accounting to $6.64 \%$ of the total cases (Fig. 2). Pemphigus vulgaris was the commonest diagnosis in group IV constituting to $4.19 \%$ followed by bullous pemphigoid (Fig. 3) accounting for $1.74 \%$ and Leprosy accounting for $31.81 \%$ in group V lesions (Fig 4). Basal cell carcinoma (Fig. 5) and intradermal nevus (Fig. 6) each accounting for $1.74 \%$ among group VI lesions.

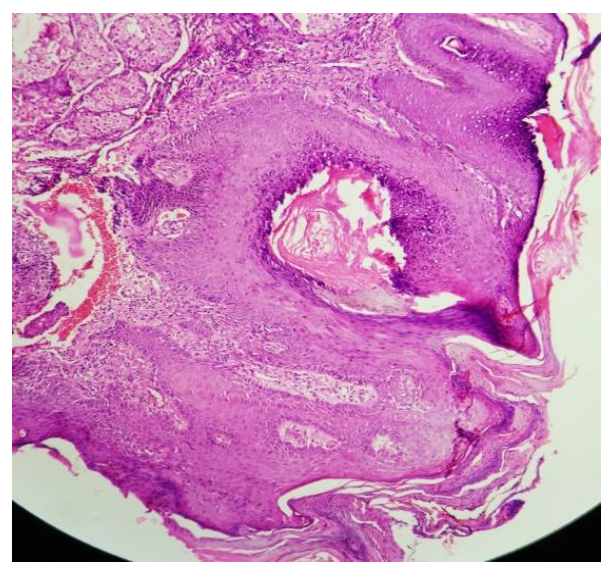

Fig. 1: Porokeratosis H\&E (100x)

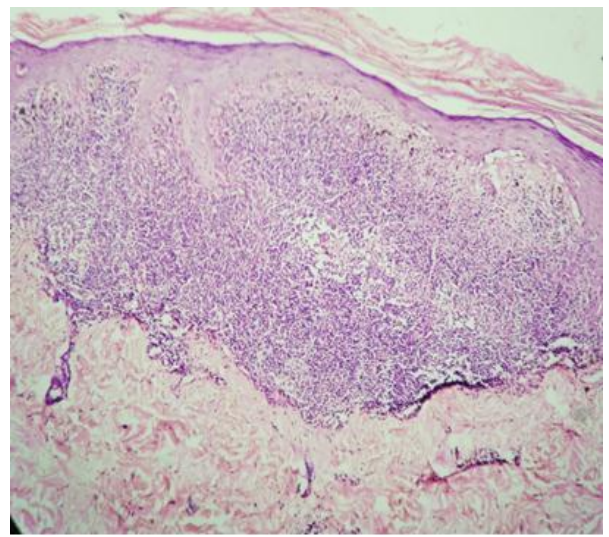

Fig. 2: Lichen planus H\&E (100x)

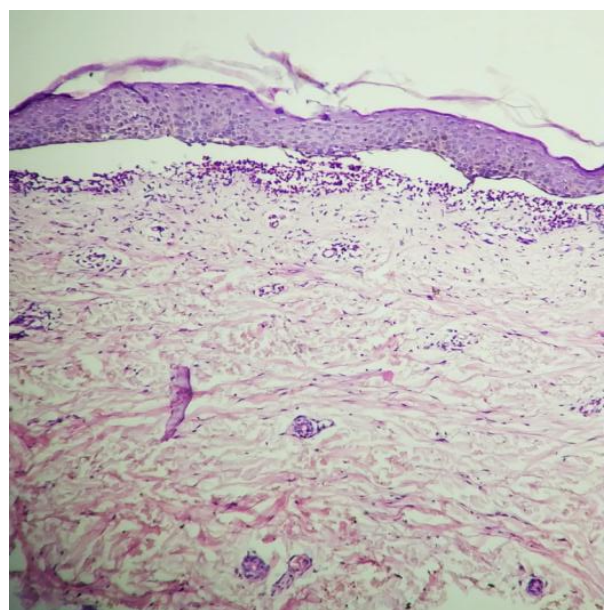

Fig. 3: Bullous pemphigoid $H \& E$ (100x) 


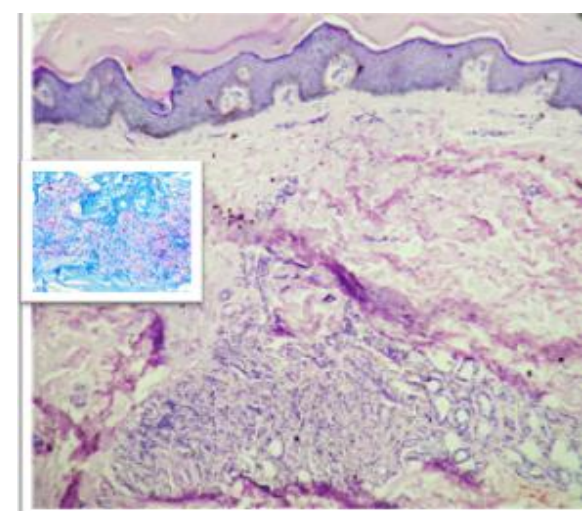

Fig. 4: Lepromatous leprosy H\&E (100x). Insite: Fite Faracco stain showing acid fast lepra bacilli

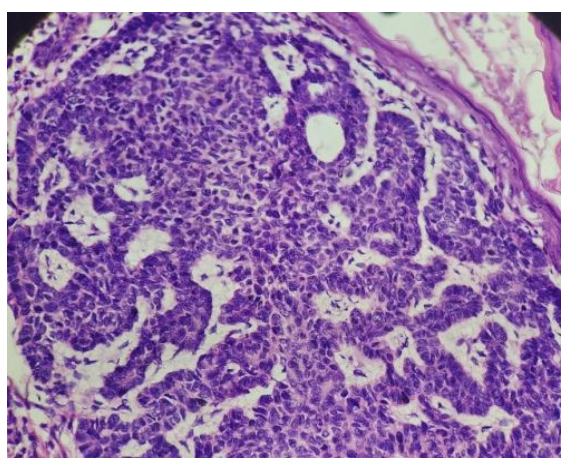

Fig 5: Basal cell carcinoma (400x)

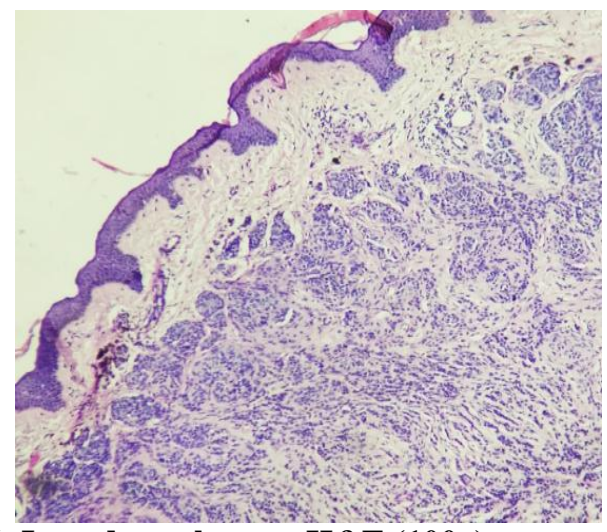

Fig. 6: Intradermal nevus H\&E (100x)

Table 1: Distribution of cases according to age and sex

\begin{tabular}{|c|c|c|c|c|c|c|}
\hline \multirow{2}{*}{ Age group } & \multicolumn{2}{|c|}{ Male } & \multicolumn{2}{c|}{ Female } & Total & Percentage \\
\cline { 2 - 7 } & $\mathbf{N}$ & $\mathbf{\%}$ & $\mathbf{N}$ & $\mathbf{\%}$ & $\mathbf{N}$ & $\mathbf{\%}$ \\
\hline $1-10$ & 8 & 5.88 & 11 & 7.33 & 19 & 6.64 \\
\hline $11-20$ & 13 & 9.55 & 17 & 11.33 & 30 & 10.48 \\
\hline $21-30$ & 28 & 20.58 & 27 & 18.00 & 55 & 19.23 \\
\hline $31-40$ & 27 & 19.85 & 23 & 15.33 & 50 & 17.48 \\
\hline $41-50$ & 21 & 15.44 & 27 & 18.00 & 48 & 16.78 \\
\hline $51-60$ & 33 & 24.26 & 39 & 26.00 & 72 & 25.17 \\
\hline$>60$ & 05 & 3.67 & 06 & 4.00 & 11 & 3.84 \\
\hline Total & 136 & 100.00 & 150 & 100.00 & 286 & 100 \\
\hline
\end{tabular}

Table 2: Categorisation of diseases according to groups (II and III)

\begin{tabular}{|c|l|c|c|}
\hline Groups & \multicolumn{1}{|c|}{ Diseases } & N & \% \\
\hline Group II & Porokeratosis & 4 & 1.39 \\
\cline { 2 - 4 } & $\begin{array}{l}\text { Inflammatory linear verrucous epidermal } \\
\text { nevus }\end{array}$ & 1 & 0.34 \\
\cline { 2 - 4 } & Psoriasis & & \\
\cline { 2 - 4 } & Seborrheic keratosis (acanthotic type) & 1 & 0.34 \\
\cline { 2 - 4 } & Wart & 1 & 0.34 \\
\hline Group III & Lichen planus & 19 & 0.34 \\
\cline { 2 - 4 } & Psoriasis vulgaris & 7 & 2.44 \\
\cline { 2 - 4 } & Lichen sclerosis et atropicus & 5 & 1.74 \\
\cline { 2 - 4 } & Contact dermatitis & 3 & 1.04 \\
\cline { 2 - 4 } & Hypertrophic lichen planus & 3 & 1.04 \\
\cline { 2 - 4 } & Atopic dermatitis & 2 & 0.69 \\
\cline { 2 - 4 } & Allergic contact dermatitis & 1 & 0.34 \\
\cline { 2 - 4 } & Chronic actinic dermatitis & 1 & 0.34 \\
\cline { 2 - 4 } & Exfoliative dermatitis & 1 & 0.34 \\
\hline
\end{tabular}




\begin{tabular}{|l|l|c|c|}
\hline & Follicular lichen planus & 1 & 0.34 \\
\cline { 2 - 4 } & Pityriasis rosea & 1 & 0.34 \\
\cline { 2 - 4 } & $\begin{array}{l}\text { Pytriasis lichenoids et varioliformis acuta } \\
\text { (pleva) }\end{array}$ & 1 & 0.34 \\
\cline { 2 - 4 } & Urticarial vasculitis & 1 & 0.34 \\
\hline
\end{tabular}

Table 3: Group IV lesions

\begin{tabular}{|l|l|c|c|}
\hline & \multicolumn{1}{|c|}{ Disease } & N & \% \\
\hline Group IV & Pemphigus vulgaris & 12 & 4.19 \\
\cline { 2 - 4 } & Bullous pemphigoid & 5 & 1.74 \\
\cline { 2 - 4 } & Darier's disease & 3 & 1.04 \\
\cline { 2 - 4 } & Pemphigus foliaceous & 3 & 1.04 \\
\cline { 2 - 4 } & Pustular psoriasis & 2 & 0.69 \\
\cline { 2 - 4 } & Atopic dermatitis & 1 & 0.34 \\
\cline { 2 - 4 } & Hailey hailey disease & 1 & 0.34 \\
\hline
\end{tabular}

Table 4: Group V lesions

\begin{tabular}{|l|c|c|}
\hline \multicolumn{1}{|c|}{ Diseases } & N & \% \\
\hline Leprosy cases & 91 & 31.81 \\
\hline Cutaneous small vessel vasculitis & 8 & 2.79 \\
\hline Morphea & 8 & 2.79 \\
\hline Small vessel vasculitis & 5 & 1.74 \\
\hline Systemic sclerosis & 5 & 1.74 \\
\hline Atrophoderma & 3 & 1.04 \\
\hline Lupus vulgaris & 3 & 1.04 \\
\hline Granuloma annulare & 2 & 0.69 \\
\hline Granulomatous chelitis & 2 & 0.69 \\
\hline Keloid & 2 & 0.69 \\
\hline PMLE & 2 & 0.69 \\
\hline Lymphocytic vasculitis & 2 & 0.69 \\
\hline Systemic lupus erythematosus & 2 & 0.69 \\
\hline Sweets syndrome & 2 & 0.69 \\
\hline Cutaneous tb-lupus vulgaris & 1 & 0.34 \\
\hline Erythema ab igne & 1 & 0.34 \\
\hline Kyrle disease & 1 & 0.34 \\
\hline Lipoid proteinosis & 1 & 0.34 \\
\hline Papulonecrotic tuberculid & 1 & 0.34 \\
\hline Scleredema & 1 & 0.34 \\
\hline Tuberculosis verrucosa cutis & 1 & 0.34 \\
\hline
\end{tabular}

Table 5: Group VI, VII, VIII cases

VI, VII, VIII cases
\begin{tabular}{|l|l|c|c|}
\hline \multirow{4}{*}{ Group VI } & \multicolumn{1}{|c|}{ Disease } & N & $\%$ \\
\cline { 2 - 4 } & Intradermal nevus & 5 & 1.74 \\
\cline { 2 - 4 } & Basal cell carcinoma & 5 & 1.74 \\
\cline { 2 - 4 } & Nevus sebaceous & 3 & 1.04 \\
\cline { 2 - 4 } & Mastocytoma & 2 & 0.69 \\
\cline { 2 - 4 } & Milia & 2 & 0.69 \\
\cline { 2 - 4 } & Mod diff squamous cell carcinoma & 2 & 0.69 \\
\cline { 2 - 4 } & Trichoepithelioma & 2 & 0.69 \\
\cline { 2 - 4 } & Eruptive xanthoma & 1 & 0.34 \\
\cline { 2 - 4 } & Giant congenital melanocytic nevus & 1 & 0.34 \\
\cline { 2 - 4 } & Hidradenoma & 1 & 0.34 \\
\cline { 2 - 4 } & Malignant melanoma & 1 & 0.34 \\
\cline { 2 - 4 } & Mastocytosis & 1 & 0.34 \\
\cline { 2 - 4 } & Melanocytic nevus & 1 & 0.34 \\
\cline { 2 - 4 } & Plane xanthoma & 1 & 0.34 \\
\hline
\end{tabular}




\begin{tabular}{|l|l|c|c|}
\hline \multirow{4}{*}{ Group VII } & Spider nevus & 1 & 0.34 \\
\cline { 2 - 4 } & Syringocystadenoma papilliferum & 1 & 0.34 \\
\cline { 2 - 4 } & Syringoma & 1 & 0.34 \\
\cline { 2 - 4 } & Trichodiscoma & 1 & 0.34 \\
\cline { 2 - 4 } & Discoid lupus erythematosus & 10 & 3.49 \\
\cline { 2 - 4 } & Alopecia areata & 3 & 1.04 \\
\cline { 2 - 4 } & Hidradenitis suppurativa & 1 & 0.34 \\
\cline { 2 - 4 } & Lichen spinulosis & 1 & 0.34 \\
\hline \multirow{3}{*}{ Group VIII } & Panniculitis & 3 & 1.04 \\
\cline { 2 - 4 } & Erythema nodosum & 1 & 0.34 \\
\hline
\end{tabular}

\section{Discussion}

Skin lesions are common in both males and females. They are heterogenous with wide clinical and histopathological spectrum. Histopathological examination of the skin biopsies is the gold standard technique for confirmation of the diagnosis. Skin biopsy is easy, simple, inexpensive and outpatient procedure which provides adequate material for confirmation of the clinical diagnosis and further follow up. ${ }^{7}$

The present study is a retrospective study in which we included all the skin biopsies received at the histopathology section in Pathology department for the period of two years. Totally 286 cases were included in the study. Out of this, 136 cases were male and 150 were female with wide age groups involved.

In our study, maximum number of cases belonged to 51-60 years of age group with females predominating the group $(52.4 \%)$. This finding was different when compared with the study conducted by Narang et $\mathrm{al}^{2}$ and Grover et al. ${ }^{8}$ In Narang et $\mathrm{al}^{2}$ study, maximum number of cases were in the age group of 21-30 years with males predominating the group (30.20\%). Grover et $\mathrm{al}^{8}$ observed that $11-20$ years age group was commonest with predominance of males in their study constituting to $68 \%$.

Skin lesions were categorized in to 8 groups depending on the histomorphological features. Out of 286 cases, majority were belonging to group Vgranulomatous lesions (154 cases), followed by group III (46 cases), group IV (27 cases), group VI (27 cases), group VII (16 cases), group II (12 cases) and group VIII (4cases).

Group V lesions were commonest in our study constituting to 154 cases $(53.84 \%)$, out of which leprosy cases constituted to about $91(31.81 \%)$ cases forming the majority of the group, followed by cutaneous small vessel vasculitis $(2.79 \%)$ and morphea (2.79\%) constituting to 8 cases each. These findings were correlated with the study done by Narang et $\mathrm{al}^{2}$ in which group $\mathrm{V}$ lesions were the commonest constituting to $24.8 \%$ out of which Leprosy was reported to be the commonest accounting to $70.76 \%$ of group V lesions. Also in a study done by Das S et al, ${ }^{11}$
Leprosy cases accounted for only 5.64\% of the total cases, which is not correlating with our study findings.

Out of 91 Leprosy cases, most commonest was Borderline Tuberculoid (39 cases) followed by Lepromatous Leprosy (25 cases), Borderline Lepromatous (10 cases), Tuberculoid (5 cases), Mid Borderline and Histoid (4 cases each) and Indeterminate (3 cases). Fite Foraco stain was done to determine the bacillary index in these cases. Leprosy being the commonest disease in our study needs strengthening of the measures to control the same.

Group III lesions being the second most common lesions in our study constituted to 46 cases $(16.08 \%)$ with Lichen planus $(6.64 \%)$ as the most common entity followed by Psoriasis vulgaris $(2.44 \%)$. These findings were not in correlation with Narang et al. ${ }^{2}$ They reported only $3 \%$ of cases belonging to category III with lesions including Psoariasis, Lichen Planus and Lichen Planus et Atrophicus.

Group IV lesions-In the present study, $19.9 \%$ of lesions belonged to this group with Pemphigus Vulgaris $(4.19 \%)$ as the commonest lesion followed by bullous pemphigoid (1.74\%).

Group VI lesions-Intradermal nevus and Basal cell carcinoma were the commonest followed by nevus sebaceous.

Group VII lesions-Discoid lupus erythematosus was the commonest followed by Alopecia areata

Group VIII lesions- Few cases of Panniculitis and Erythema nodosum were noted.

In our study, we did not encounter any lesion belonging to category 1 . This is in correlation with the study done by Narang et $\mathrm{al}^{2}$ in which only 3 cases were reported in group 1.

Distribution of cases in different categories showed findings which varies from other such studies which can be attributed to geographic, environmental and causative factors.

\section{Conclusion}

Study of dermatological lesions and its categorization has been done to know the prevalence of various skin diseases in our hospital. Dermatological lesions are heterogeneous with wide age distribution, clinical and histopathological spectrum. Skin biopsy is easy, simple, inexpensive and outpatient procedure 
which provides adequate material for confirmation of the clinical diagnosis and further management. Histopathological examination of the skin biopsy remains the gold standard for diagnosis which can be supported with the other techniques to confirm the diagnosis. Leprosy being the commonest disease in our study needs strengthening of the measures to control the same.

\section{References}

1. Gaikwad SL, Kumawat UD, Sakhare NA, D'costa GF. Histopathological Spectrum of Skin Lesions- Experience at Rural Based Hospital. Int J cur Res.2016 Aug;8(8):36223-7.

2. Narang S, Jain R. An evaluation of histopathological findings of skin biopsies in various skin disorders. APALM. 2015 Jan-Mar;2(1):A42-6.

3. Agarwal D, Singh K, Saluja SK, Kundu PR, Karma H. Histopathological Review of Dermatological Disorders with a Keynote to Granulomatous Lesions: A Retrospective Study. Int J Sci Stud. 2015;3(9):66-9.

4. Mehar R, Jain R, Kulkarni CV, Narang S, Meena M, Patidar H. Histopathological study of dermatological lesions- A retrospective approach. Int J Med Sci Public Health. 2014;3:1082-5.
5. Mruthyunjayappa S, Mahantappa H, Gopal MG, Venugopal SB. A Study of Histopathological Features in Patients Presenting withHyperpigmented Skin Lesions. Arch Med Health Sci. 2016;4:189-95.

6. Goyal N, Jain P, Malik R, Koshti A. Spectrum of Non Neoplastic Skin Diseases: A Histopathology Based Clinicopathological Correlation Study. Sch J App Med Sci. 2015;3(1F):444-9.

7. Singh S, Debnath A, Datta D, Chakravarty S, Chaubey RN. Histopathological Evaluation of Skin Lesions with Special Reference to Skin Adnexal Tumors in a Tertiary Centre of North-Eastern India- A Three Year Study. IOSR-JDMS. 2016 Feb;15(2):34-9.

8. Grover S, Agale SV, D'costa GF, Valand AG, Gupta VK. Clinico- Histopathological Spectrum of Infectious Granulomatous Dermatoses in Western India-A Representative Study from Mumbai. J Clin Diagn Res. 2016 Apr;10(4):10-4.

9. Veldurthy VS, Shanmugam C, Sudhir N, Sirisha O, Motupalli CP, Rao N et al. Pathological study of nonneoplastic skin lesions by punch biopsy. Int J Res Med Sci. 2015;3(8):1985-8.

10. Shrestha A, Chauhan S, Mathur M. Clinicopathological Correlation of leprosy. J Path Nep. 2017;7:1095-02.

11. Das S, Chatterjee T. Pattern of skin diseases in a peripheral hospital's skin OPD. Ind J Derm 2007;52:935. 